\title{
Is conventional coronary artery surgery being replaced by the hybrid approach?
}

\author{
Tomas A. Salerno, MD, ${ }^{\mathrm{a}}$ and Alexander C. Ferreira, $\mathrm{MD}^{\mathrm{b}}$
}

\footnotetext{
From the ${ }^{\mathrm{a}}$ Division of Cardiothoracic Surgery, University of Miami Miller School of Medicine, and ${ }^{\mathrm{b}}$ Department of Cardiology, Jackson Memorial Hospital, Miami, Fla.

Disclosures: Authors have nothing to disclose with regard to commercial support.

Received for publication Feb 8, 2016; accepted for publication Feb 10, 2016; available ahead of print March 8, 2016.

Address for reprints: Tomas A. Salerno, MD, Division of Cardiothoracic Surgery, University of Miami Miller School of Medicine and Jackson Memorial Hospital, 1611 NW 12th Ave, Miami, FL 33136 (E-mail: tsalerno@med.miami.edu).

J Thorac Cardiovasc Surg 2016;151:1702-3

$0022-5223 / \$ 36.00$

Copyright $(2016$ by The American Association for Thoracic Surgery

http://dx.doi.org/10.1016/j.jtcvs.2016.02.023
}

Nearly 2 decades ago, Angelini and colleagues ${ }^{1}$ proposed the concept of hybrid myocardial revascularization. The concept was to incorporate the benefits of a reliable arterial graft (left internal mammary artery to left anterior descending artery [LIMA-LAD]), eliminating some of the inherent risks of complete revascularization due to cardiopulmonary bypass, aortic manipulation, and stroke, and avoidance of morbidity associated with venous conduit harvesting. Despite the attractiveness of this approach, however, the hybrid procedure was plagued by the somewhat disorienting experience of logistically combining the 2 procedures. At that time, hybrid operating room/catheterization suites were not yet in widespread use to allow both procedures to be done in a single setting. Staging the procedures created a vexing dilemma of either performing first the LIMA-LAD graft and having the benefit of evaluating graft patency at the time of stenting the lateral/inferior vessels, but risking a second operation if a catastrophic complication occurred during the stenting procedure. Alternatively, perform stenting first and then LIMA-LAD anastomosis on dual antiplatelet therapy, thus adding a significant risk of bleeding.

Over the last 20 years, surgery has evolved to incorporate various combinations of arterial conduit options, Y-grafting, off-pump surgery, and endoscopic vein harvesting. Stenting technology also is evolving, with more reliable, ever-improving drug-eluting platforms, bioabsorbable polymers and scaffolds, and new techniques for addressing chronic occlusions and complex lesions. It appeared that the 2 competing fields were moving apart, as each attempted to provide the most complete revascularization with the lowest possible morbidity.

Recent advances in structural heart procedures and widespread investment in hybrid procedure rooms, along with the creation of heart teams, have brought collaboration between interventional cardiologists and cardiac surgeons to new heights. Contemporaneously, long-term trials with DES have reported patency rates of $>80 \%$ at 10 years, ${ }^{2}$

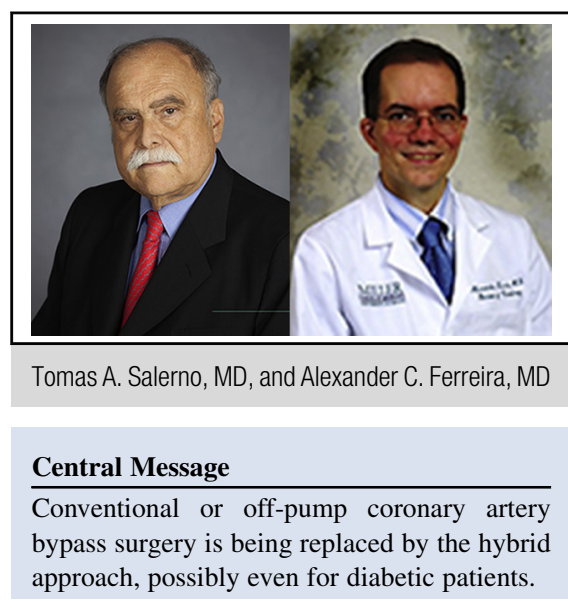

See Article page 1695 . apparently superior to the $<50 \%$ rate of vein graft patency from surgical trials. ${ }^{3}$ Furthermore, recent clinical trials, including SYNTAX (Synergy Between PCI With Taxus and Cardiac Surgery) ${ }^{4}$ and FREEDOM (Future Revascularization Evaluation in Patients With Diabetes Mellitus: Optimal Management of Multivessel Disease), ${ }^{5}$ have added to the evidence reported from the BARI (Bypass Angioplasty Revascularization Investigation) trial ${ }^{6}$ linking the survival advantage of surgery, particularly in patients with diabetes, to the use of an LIMA graft. Revisiting a hybrid strategy became unavoidable.

The question then is: If the patency rate of a stent is superior to that of a vein graft, why should surgeons subject a patient to full sternotomy with either off-pump coronary artery bypass (OPCAB) or conventional coronary artery bypass grafting? The claim has been made that in patients with diabetes, clinical trials have shown the superiority of surgery over stenting. Now that stent technology has mostly surpassed venous conduits, should patients with diabetes then receive a hybrid approach of arterial grafts (LIMALAD), followed by stents of lateral and inferior vessels?

In this issue of the Journal, Song and colleagues, ${ }^{7}$ in a retrospective single-center study of patients with diabetes undergoing a hybrid surgical approach $(\mathrm{n}=120)$ and a propensity-matched cohort of patients undergoing OPCAB $(\mathrm{n}=240)$, report clinical benefits of the hybrid approach, including less chest tube drainage, lower transfusion rate, shorter mechanical ventilation time, and shorter intensive care unit stay. At 30 months postsurgery, the 2 groups had 
a similar rate of major adverse cardiac and cerebrovascular events, except for a lower rate of stroke in the hybrid group.

Along with the retrospective single-center nature of the study population and the relatively short duration of follow-up, this study may have a number of potential confounders. First, the statistical method of propensity matching can only partially account for all potential variables for allocation bias. Although at first glance it appears that baseline clinical characteristic are matched, a number of clinical variables, although available, were not included in the propensity score model. Second, although the total number of diseased vessels was the same in the 2 groups, it appears that the total number of stents used was lower than the number of vein grafts performed, suggesting that the $\mathrm{OPCAB}$ population either had more extensive disease or underwent more complete revascularization. Third, the cutoff for stenosis severity at $50 \%$ might be appropriate for deciding which vessels to graft. Because the great majority of those $50 \%$ lesions are not hemodynamically significant, as in the FAME trial, ${ }^{8}$ and flow measurements were not made to assess severity and guide stent utilization, a number of those lesions could have been left untreated, further improving the results of the hybrid population. Fourth, the great majority of patients were treated with firstgeneration drug-eluting stents (DES). Newer-generation DES, by virtue of their thinner struts and more biocompatible polymers, may be associated with better deliverability, less side branch occlusion, faster healing, and lower risk of thrombosis. Finally, the short duration of the study may underestimate some of the true benefits of stents in allowing patency of native vessels. Grafted native vessels frequently occlude, and intervention of degenerated vein grafts, mainly when performed more than 5 years after implantation, is frequently complicated by distal embolization, absence of reflow, and periprocedural infarct, even when filters are used.

As noted by Angelini and colleagues, ${ }^{1}$ by foresight or serendipity, "the most effective way of predicting the future is inventing it." Despite the lack of randomized trial data, all of the available clinical evidence points to a hybrid approach as the way of the future.

\section{References}

1. Angelini GD, Wilde P, Salerno TA, Bosco G, Calafiore AM. Integrated left small thoracotomy and angioplasty for multivessel coronary artery revascularisation. Lancet. 1996;347:757-8.

2. Sousa JE, Costa JR Jr, Abizaid A. 10-year follow-up of the first Cypher stent implanted in human: an invasive evaluation with angiography, intravascular ultrasound, and optical coherence tomography. JACC Cardiovasc Interv. 2010;3: 556-8.

3. Goldman S, Zadina K, Moritz T, Ovitt TW, Sethi G, Copeland JG. Long-term patency of saphenous vein and left internal mammary artery grafts after coronary artery bypass surgery: results from a Department of Veterans Affairs Cooperative Study. J Am Coll Cardiol. 2004;44:2149-56.

4. Groot MW, Head SJ, Bogers AJ, Kappetein AP. Coronary revascularization in diabetic patients: a focus on the 3-year SYNTAX trial outcomes. Herz. 2012;37. 281-6.

5. FREEDOM Trial Investigators. Strategies for multivessel revascularization in patients with diabetes. $N$ Engl J Med. 2012;367:2375-84.

6. Bypass Angioplasty Revascularization Investigation (BARI) Investigators. Comparison of coronary bypass surgery with angioplasty in patients with multivessel disease. N Engl J Med. 1996;335:217-25.

7. Song Z, Shen L, Zheng Z, Xu B, Xiong H, Li L, et al. One-stop hybrid coronary revascularization versus off-pump coronary artery bypass in patients with diabetes mellitus. J Thorac Cardiovasc Surg. 2016;151:1695-701.e1.

8. De Bruyne B, Fearon WF, Pijls NH, Barbato E, Tonino P, Piroth Z, et al; FAME 2 Trial Investigators. Fractional flow reserve-guided PCI for stable coronary artery disease. N Engl J Med. 2014;371:1208-17. 